\title{
Active Teaching and Learning Methodologies: Some Considerations
}

\author{
Clóvis Luís Konopka1, Martha Bohrer Adaime², Pedro Henrique Mosele1 \\ ${ }^{1}$ Faculty of Medicine, Federal University of Santa Maria, Santa Maria, Brazil \\ ${ }^{2}$ Faculty of Chemistry, Federal University of Santa Maria, Santa Maria, Brazil \\ Email: cloviskonopka@gmail.com
}

Received 14 July 2015; accepted 9 August 2015; published 12 August 2015

Copyright (C) 2015 by authors and Scientific Research Publishing Inc.

This work is licensed under the Creative Commons Attribution International License (CC BY).

http://creativecommons.org/licenses/by/4.0/

(c) (i) Open Access

\begin{abstract}
Drawing the students' attention and keeping them engaged are essential points to the learning process. Active methodologies place the students at the center of this process and make them the protagonists of discovery, rather than just passive information receivers. There are different teaching strategies to create an active learning environment and to engage the students to it. Current evidences indicate that active learning improves understanding and information retention. It is also effective in developing higher-order cognitive skills. Nevertheless, the adoption of active methodologies is still low. The authors of the current paper encourage the reflection on the traditional teaching practices and suggest that the active methodologies are an education option for secondary and higher education level courses as a way to meet nowadays needs in education.
\end{abstract}

\section{Keywords}

Active Methodologies, Active Learning, Teaching Strategies, Individual Learning, Cooperative Learning

\section{The Cardiovascular System in a Biology Lesson}

It was fully confirmed, by reasoning and by eye experiments, that the pulse of the ventricles forces the blood through the lungs and the heart, and sends it to the whole body. It, then, flows through the arteries and pores of the flesh, and flows back through the veins from all points to the center, from the smallest to the largest veins, and from them to the vena cava, until it finally gets to the right atrium of the heart [...]. It is, therefore, necessary to conclude that the blood flows in a circular and perpetual motion in animals and the only cause of this motion lies on the heart, which exerts this action or function by compression or pulse (Harvey, 1628: p. 68). 
Let us imagine the following scenario: Monday morning in a biology lesson and the subject of the integration between cardiovascular system morphology and physiology.

The teacher decides to do something new and different. He suddenly says: "Now, let's split the entire class into groups of two or three participants. Within a few minutes, you will tell me the direction and how the blood flows in the veins you can see in your forearms—-something the English physician William Harvey (1578-1657) correctly demonstrated, in a very simple way, by eye observation, in 1628. By doing so, you will understand the circular motion of the blood, and you will also understand that arteries and veins are different routes of the circulatory system. Now, come on!”

Amazed and curious at the same time, the students quickly form groups and begin the task. The teacher demands the answer from each group, listens to more voluntary responses and encourages the cooperation among students through the interaction of ideas and experiences. Some groups offer practical demonstrations of their conclusions. Surprised, the teacher then continues the lesson using the original illustration of the classic experiment by William Harvey (Figure 1). This illustration was extracted from his first book published in Frankfurt (Germany) in 1628, Exercitatio anatomica de motu cordis et sanguinis in animalibus (anatomical study on the motion of the heart and blood in animals), which clearly demonstrated the unidirectional blood flow in a superficial vein of the human body forearm, which was aided by the presence of venous valves ${ }^{1}$.

The whole activity does not last more than fifteen minutes, and the entire class is motivated, participative and actively engaged with the topic.

At the end of this innovative educational experience, some students reported that, sometimes, they read in newspapers or magazines and even heard on television the misleading terms "vein artery" or "aorta vein", although this issue was explained almost 400 years ago ${ }^{2}$ !

The innovative teaching procedures adopted by the teacher in this fictional scenario- the formation of student groups-were active learning strategies, which had in common the active involvement by the students in their learning process. Most teachers know the topic and are sometimes advised by experienced colleagues to always use these strategies to supplement their lessons.

\section{Initial Considerations}

The active methodologies engage students in the learning process through activities and/or debates in the classroom, instead of passively listening to the teacher. They emphasize higher-order thinking and often involve teamwork (Freeman et al., 2014: p. 8411).

Traditional lessons, which are focused on the teacher, have been used as dominant educational strategy since the first universities were launched in Western Europe, over 900 years ago (Brockliss, 1996: p. 565). However, recent studies have questioned the effectiveness of this teaching model and, at the same time, discussed the need for the construction of knowledge by the students themselves. Thus, it brought the strategies based on active methodologies to the mainstream (Freeman et al., 2014: p. 8411).

Luckesi (1994) discusses the teaching procedures in school daily routines and argues:

Do we teachers - when we establish our education plan, or when we decide what to do in class - wonder whether the teaching techniques we use are coherently coordinated with our pedagogical proposal? Or, do we choose the teaching procedures based on their modernity, or because they are easy, or because they mean less work to the teacher? Or, even worse, do we choose the teaching procedures without any specific criterion?

Current studies on metacognition, self-regulated learning, learning environments and learning styles have offered several positive initiatives to the search for innovative school practices (Beichner, 2014: p. 10; Boekaerts, 2012: p. 3).

\footnotetext{
${ }^{1}$ William Harvey demonstrated that the circular motion of blood in the human body begins in the heart, which pumps it through the arteries. Then, the blood returns through the veins to the heart, thus completing the circulation. In 1628, when he published his conclusions, Harvey was unaware of the existence of capillaries connecting arteries and veins, fact that was discovered by Marcello Malpighi (1628-1694) in 1661, four years after Harvey’s death (apud Ramos, 1992: p. 561).

${ }^{2}$ Harvey's experiment is very simple and didactic, and it can be easily reproduced in the classroom as follows: Place a little-tight tourniquet (not to interrupt arterial circulation) above the elbow of a volunteer to cause the engorgement of the forearm veins, which path will present spaced nodular dilations, corresponding to the valves. By pressing a finger on one vein below the dilation, and by sliding the finger in the distal direction $(\mathrm{H})$, it is possible to see that the blood does not go down to occupy the bloodless part, due to valve action. On the other hand, by pressing the vein bellow the dilation, and by sliding another finger immediately above it in proximal direction (O), it is possible to see that the segment between the fingers $(\mathrm{O}-\mathrm{H})$ is bloodless, but it fills with blood when the first finger is removed $(\mathrm{H})$. Thus, Harvey concluded that the role of venous valves is to prevent blood reflux to the limbs, ensuring that blood always moves towards the heart.
} 


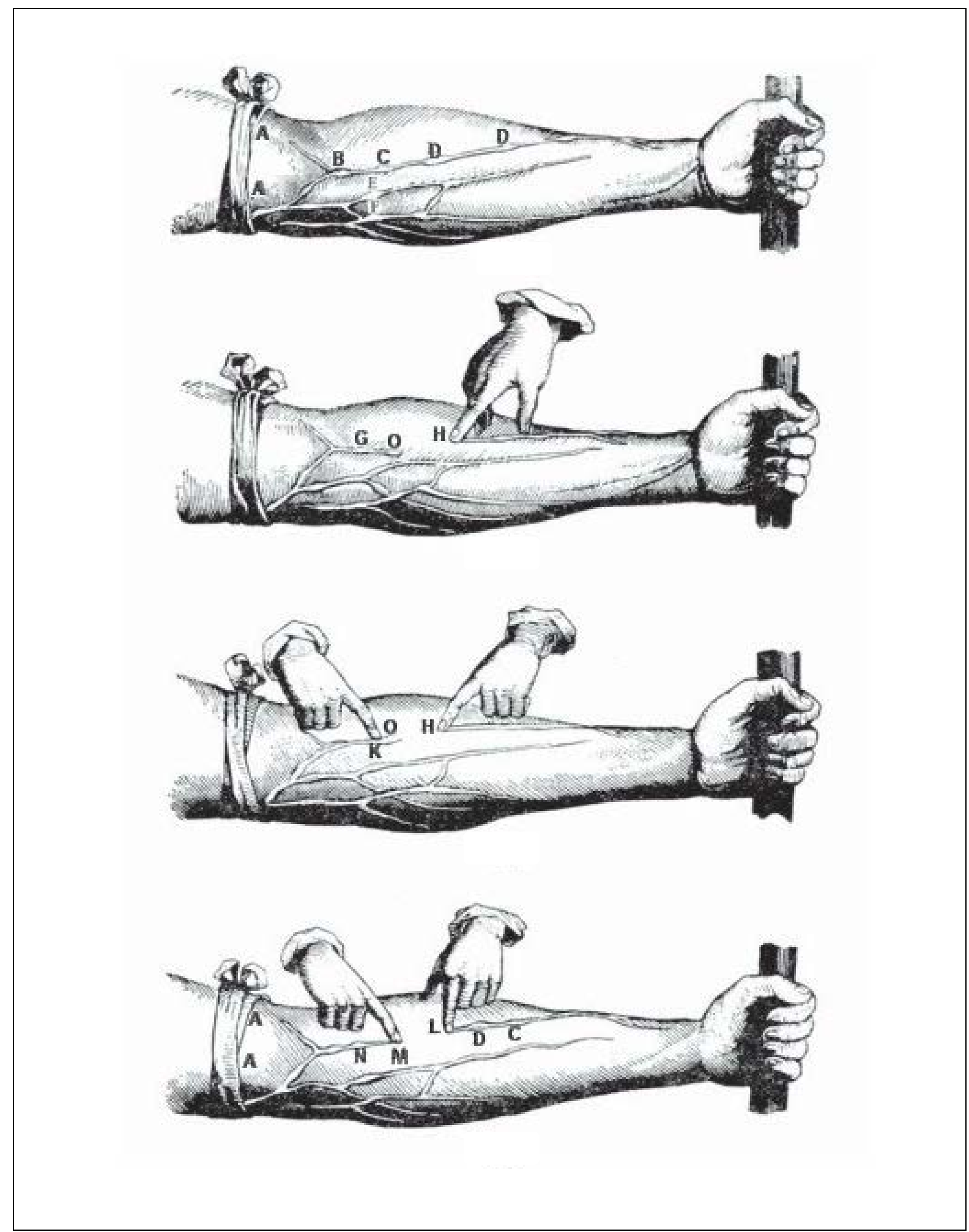

Figure 1. Original illustration of William Harvey's experiment published in 1628, which demonstrates the blood returning through the veins toward the heart, aided by the presence of valves (Harvey, 1628: p. 66).

However, Boekaerts (1997: p. 152) highlights that, although these studies demonstrate the effectiveness of innovations in these topics, no changes have been seen in school environments, because 
[...] most classrooms are still occupied by students that are not engaged with their learning process. In most cases, teachers direct and guide the learning process, a situation that does not invite students to use and develop their cognitive and motivational skills. Given this scenario, it is expected that students just reproduce and apply the new information presented or made available by the teacher to them.

The discussion about active learning often triggers heated debates because the subject is presented (or wrongly perceived) as a radical proposition to replace traditional lessons, when, in fact, it is about techniques that complement them. Much of the controversy is justified by the tension between maintaining tradition and the need for innovation in school environments. However, all those involved in this process realize that the current education needs to improve its results to meet the contemporary society demands.

Traditional discursive classes focused on the teacher constitute the dominant strategy at any education level. These classes are considered to be highly effective in synthesizing and communicating complex information, especially when it comes to short time crowded classes of disciplines with reduced curricular space (Lom, 2012: p. 64).

On the other hand, active learning methodologies have strongly drawn the attention of teachers who are concerned with awakening and keeping their students' interest and creativity. These teachers seek complementary interactive and motivating alternatives to traditional teaching methods. Meanwhile, the skeptic education professionals keep on seeing these methodologies as a passing novelty or as a simple fad from few enthusiasts in education, rather than a real teaching strategy.

Even when teachers are interested in learning new teaching practices, there are several challenges to their effective implementation. There is lack of clarity regarding the definition of active learning, which may cause uncertainties in its implementation (Borrego, 2013: p. 394).

Although this is a recurrent scenario within the educational environment, there are still doubts about what in fact active learning means and how it differs from the traditional teaching methodologies. Some teachers do not even understand how the most common teaching strategies based on active learning differ from each other. Many of these teachers think they have enough activity when students ask questions in class, when they are doing their homework or during the practical activities carried out in laboratories. In addition, others cannot find the answers to their doubts in the literature, because they somehow consider the subject confusing and find its effectiveness difficult to measure and interpret. It happens because "there are not many quantitative analyses in the literature that clearly compare the results between instructionist and constructionist methods" (Freeman et al., 2014: p. 8412). Given this context and the existing difficulties, most teachers prefer to follow the traditional teaching model (Fraser et al., 2014: p. 2).

Unfortunately, according to Fraser et al. (2014), "literature rarely identifies the key elements of pedagogical innovations or explains how to implement them in the classroom.” In addition, results from studies on education are often disseminated and discussed among researchers in education, and they rarely provide enough detail for those who are not researchers. These factors hinder the understanding of active learning methods and the identification of the critical elements for a successful implementation (Borrego, 2013: p. 395).

The confusion comes from the fact that different authors have different interpretations about the same words. Thus, getting consensus on certain strategies is not always possible and it affects the comparison of results. However, one may find commonly used concepts and identify their key elements, thus making it possible to highlight the existing similarities and differences.

The current paper aims to review the active methodologies as if they were instructional strategies. In addition, it discusses the main obstacles limiting the use of these methodologies as well as the precautions that should be adopted in the search for conclusions about their effectiveness. Finally, the paper summarizes some recent findings obtained through a non-systematic search for certain significant papers. This is not a complete literature review, but only a consideration drawn according to literature contributions. The authors hope that the current study may contribute to the deeper understanding of the new strategies in order to facilitate their implementation in the context of youth and adult education, and encourage the reflection on traditional teaching practices.

\section{Defining Some Key Terms}

Two important and related terms—-namely, teaching strategies and learning activities—are used at the time active learning methodologies are discussed. Teaching strategies refer to the set of structures, systems, methods, techniques, procedures and processes used by teachers during their classes in order to assist students' learning. 
On the other hand, learning activities refer to instructional tasks or activities guided by the teachers. Students perform these activities during class, individually or in groups, with or without the use of technological equipment. These two terms do not necessarily imply a passive or active instruction. For example, the teacher may choose a passive teaching strategy based on discursive or traditional lecture and the students will be just listeners. On the other hand, the teacher may choose an active teaching strategy based on problem-based learning (PBL) and at this point students will have to find the information to solve a given problem themselves. Thus, active teaching strategies comprise a set of pedagogical practices containing a variety of activities that hold a common element "engaging the students to do things and to think about what they are doing” (Bonwell \& Eison, 1991).

Active learning is the technical term for a set of pedagogical practices that address the students' learning process under a different perspective from that of classical methodologies (Gudwin, 2015; Prince, 2004: p. 224). Active learning can be defined as the process of acquiring knowledge, skills, values and attitudes by any educational strategy that involves or engages students in the process by leading them to activities and debates, instead of just putting them in the position of passively listen to the information given by the teacher (Anastasiou \& Alves, 2004: p. 68). These strategies are ideally used to complete discursive classes and help students to critically or creatively think, talk to classmates or to the entire class, express ideas through writing, explore personal attitudes and values, provide and receive feedback or to reflect on their learning process. This concept includes all practices that help students to increase information retention by fulfilling small written exercises related to the content of the lesson or by accomplishing complex group exercises applied to real life situations and/or to new problems. Therefore, active learning encompasses a wide and varied set of techniques or methods that commonly require students to perform significant proactive activities by being aware and responsible for what is being done (Prince, 2004: p. 225) ${ }^{3}$.

Although some teachers consider traditional activities such as tasks or homework as active learning, actually, just activities performed in the classroom or within school environments, such as library visits or computer searches and science lab practices are active learning procedures. The key elements for the active learning strategy are the participation and direct involvement of students in the learning processes. As for comparison purposes, this instructional strategy is often confronted with teaching methods based on traditional discursive classes, in which students passively receive information from an instructor.

When the teacher decides to use an active learning strategy it should be often used to help students to develop a better understanding of the subject, skills and attitudes (competencies to promote deep learning). Just a smaller part of the activity should be used to transmit information (to promote superficial learning). Some studies have shown that the key to a successful and significant learning appears to be the combination of positive aspects of the three approaches (Coil, 2010: p. 530).

The students' activity may manifest through individual or cooperative learning strategies.

Individual learning strategies emphasize the constructivist qualities in knowledge processing. This process ultimate goal is to develop and apply knowledge to solve problems, as well as to generate new knowledge using cognitive processes. The individual learning quality is related to the students' ability to guide their learning process, to conduct investigations and to control their learning processes. Metacognition is a key element to the individual learning.

Cooperative learning, in turn, may be defined as a teaching strategy to structured teamwork in groups composed of three or more participants targeting on common goals. Students work together to achieve a common goal and it goes against the myth of the genius and the individual achievement from isolated students. Unlike the simple teamwork when there is no guarantee that everyone will be participatory, the cooperative learning is based on highly structured learning conditions set in such a way that one student cannot take advantage of the efforts done by a classmate. Among the tasks proposed to students in this methodology, there are exercises carried out in stages, research projects, presentations and simulations. One of the most recognized and classic cooperative learning models was described by Johnson, Johnson, \& Smith (1998: p. 1-27). Their model incorporates five assumptions regarded as critical to actual cooperation: positive interdependence, individual accountability, promotive interaction, social skills and group processing. Although there are other cooperative learning

\footnotetext{
${ }^{3}$ There are numerous references in the literature describing the features, indications and forms of using a wide variety of active learning techniques. A great source in Portuguese can be found on the blog by the teacher Geraldo Magela (https://gmagela.wordpress.com) and in the book Processos de Ensinagem na Universidade: Pressupostos para as Estratégias de Trabalho em Aula (Teaching and learning processes at the University: Assumptions for Working Strategies in Class) by Anastasiou \& Alves (Orgs.), 3rd ed., 2004. An English reference source is available at http://geoffpetty.com/geoffs-books/teaching-today/, and in the book Teaching Today: a Practical Guide, by Geoff Petty, 5th ed., 2014.
} 
models, the common key element to all of them is the emphasis on encouraging cooperation rather than competition.

Cooperative learning is one of the key elements to problem-based learning due to its features.

The problem-based learning (PBL) concept is a form of cooperative learning process. It is very popular in several medical schools in different countries and has been used for over 50 years. However, it may also be applied to any other scientific field or school course. The process consists of an instructional method performed in small groups of 8 to 10 students introduced to relevant problems at the beginning of the instruction. The method is also used to provide the context and to motivate learning through a sequence of distinct steps (Moreira \& Manfroi, 2011: p. 479).

This method was developed from scientific findings on human memory functioning and other cognitive functions. It considers that memory and knowledge recovery is stronger when it is linked to contexts. PBL is always active and, most of the time, it is collaborative or cooperative. The process requires a physical and organizational structure that allows students to permanently access books, journals, internet and other sources, as well as adequate training to teachers. PBL demands less time preparing, studying and updating lectures, but it demands teachers to develop different skills, including good oratory. The educator must play the leading role in the group and be trained to properly follow the methodology; however, he/she must keep the students focused on learning and he/she cannot make mistakes and bring the focus back to the teacher. This strategy concerns learning the information, but also seeks the acquirement of other important skills such as self-directed learning, critical thinking and reasoning, the search and the use of educational resources, communication, teamwork and leadership (Kwan, 2009: p. 92).

\section{What the Literature Say about It: The Evidence of Active Learning}

Active learning is based on old concepts of learning from experience, when "knowledge is built through experience transforming" (Dewey, 1938). These teaching techniques use the 'generation effect' in learning and memory science. According to these techniques there is better learning when students produce information instead of passively receive it (Slamecka, 1978: p. 592). In addition, many studies have shown that students retain more information when they handle it at higher Bloom's Taxonomy levels (application, analysis, synthesis and evaluation) due to the need for further reflection and development (Huitt, 1992: p. 34).

Unlike traditional teaching methods based on classic lessons that, in some cases, compare students to 'sponges' or depositaries of knowledge, the "banking concept of education” by Paulo Freire (2011) states that the active learning strategies emphasize constructivist qualities (Fox-Cardamone, 2003: p. 4).

The key elements to active learning are: introducing an activity in the classroom and encouraging the students to engage with this activity. It is not just the case of simply encouraging students to ask questions during class. The mere introduction of an activity in class may not lead to the expected results because its success also depends on the students' mental and physical engagement.

According to data reported by Astin (1993: p. 74), students' involvement in the process is one of the most important predictors of their academic success. In this sense, the better the activity is, the higher the students' participation and understanding of the content to be learned. Students should be challenged to work things out for themselves, so they remain always active and motivated. Therefore, the teacher should encourage students to search for information in libraries and on the Internet, discuss ideas with colleagues, develop new approaches to solve problems, and to constantly question their own level of understanding.

Hake (1998: p. 64) conducted a survey among 6000 students from a higher education course in Physics. He noticed that the students' performance after interactive engagement methods were applied was twice better that that of traditional class methods. Other studies even showed better results and reported that students showed approximately two to three times higher understanding of basic physics concepts such as force and acceleration in comparison to traditional methods (Laws et al., 1999).

Freeman et al. (2014: p. 8410) compared the performance of primary and secondary level students who were taught by the active methods in disciplines such as science, technology, engineering and mathematics (STEM) to that of traditional class students. These authors published the largest meta-analysis so far; they gathered data from 225 studies that compared the scores obtained in final exams or failure rates among students between 1942 and 2010. Their analyses revealed mean score 6\% higher in students from active learning courses in comparison to those from passive learning courses (traditional). In addition, the failure of traditional class students was 55\% 
higher than that of active methodology students. The benefits from active learning were effective in any class size; however, they were higher in classes comprising less than 50 students. According to the study, active methodologies should be somehow included in all education levels.

Eddy et al. (2015: p. 2) developed a monitoring tool applied to the use of active methodologies in higher education, namely Portaal (Practical Observation Rubric to Assess Active Learning). They concluded that both the active methodologies and the evidence-based teaching practices will soon become the main instructional method at any college center.

Marcondes et al. (2015: p. 27) developed a set of puzzles used to teach the cardiac cycle in the physiology classes of biology, dentistry, medicine, pharmacy and nursing undergraduate courses. These authors tested the method in seven higher education institutions (in the states of São Paulo, Santa Catarina and Minas Gerais, Brazil) and concluded that a simple and inexpensive puzzle game can be successfully used as active learning methodology to complete the traditional lecture about the cardiac cycle physiology.

\section{The Traditional Lecture}

[...] there is no other solution to the education issue but to realize that the best teaching requires an individual and direct relationship between the student and a good teacher-a situation in which the student discusses ideas, thinks and talks about things. It is impossible to learn a lot just by sitting in a classroom.

(Feynman, 1963).

The image that best depicts the lecture students are familiar with in their school life is that of the teacher in front of the class, standing by the board and centralizing students' attention by playing the role of knowledge transmitter through his/her discourse. Therefore, the discursive lecture, according to this archetype, is the prevalent teaching strategy in any school environment worldwide. When this technique is well prepared, organized and didactically presented it is highly effective in synthesizing and communicating complex information, especially before short time crowded classes of disciplines with reduced curricular space.

However, several evidences indicate that the passive learning inherent to this methodology is not effective in promoting deep and lasting learning or in stimulating high-level reasoning and abstraction, as it is described in the hierarchical Bloom's taxonomy learning goals classification (Bloom, 1986: p. 6). It can be explained by the fact that, as a teaching strategy, a 50-minute traditional lecture cannot keep the attention of a group of students for long. Previous studies showed that the human mind progressively loses concentration after 10 to 15 minutes under any passive situation (Stuart \& Rutherford, 1978: p. 514). This reduced concentration negatively affects information retaining, problem-solving skills, reasoning, acting, motivation and further learning abilities, as it was demonstrated by high school students described in a literature review in USA (Mckeachie, 1987: p.3).

Nevertheless, traditional lectures are still widely used. According to Ramsden (1992: p. 154), "one should not give the impression that it is impossible to give a good lesson, or that good teachers should not teach, although they should do it less and for shorter periods.”

In 2006, a study was conducted among students from the undergraduate course in computing at Macquarie University (Sydney, Australia). This study regarded the perception of these students about discursive lectures and it showed two essential aspects of a good lecture: 1) the teacher goes beyond his/her notes and 2) the lecture is more interactive, and the teacher questions the students' understanding of concepts and answers their questions. On the other hand, the same study found that a lecture was bad when the teacher 1) was just limited to read a text or some annotations, 2) criticized the students for their lack of effort and when 3) approached the content of the lessons too quickly or too slowly (Hitchens \& Lister, 2009).

\section{Obstacles Restricting the Use of Active Teaching Instructional Strategies}

One of the main obstacles faced throughout the implementation of active methodologies is represented by the students' resistance to be more proactive in their learning. This resistance is generally observed in any approach which is not based on discursive lectures because the active methodologies clearly contrast the role of passive listener the students are used to (Doyle, 2008).

However, there are practical obstacles, as well as obstacles related to the student-teacher binomial, which may limit the use of active learning instructional strategies (Bonwell \& Eison, 1991). Among the practical obstacles, there are: the limited time available to cover the entire content of the discipline in the classroom, the need for 
time to develop the strategy before its application, the difficulty in implementing the method in large classes, the idea teachers have about being good lecturers themselves, and the lack of resources, materials and support equipment.

Active learning strategies demand more time than that used by the teacher during traditional lectures and it may compromise the discipline program. However, performance tests showed increase in learning rates when the teacher simply allowed three brief intervals (three minutes) during the lesson to enable active student-student interaction (Rowe, 1980).

The time required to prepare a new active learning strategy is certainly longer than that required to prepare the traditional lecture. However, there are currently hundreds of published papers and dozens of Websites to help teachers accomplishing this task in any discipline. One of the best sources of Internet consultation is available at www.merlot.org.

The obstacles related to student and teacher are somewhat more difficult to overcome, and they include the fact that students do not actively participate in the process, learn the content, use higher-order reasoning and abstractions (deep learning) and do not positively enjoy the experience. As for the teacher, they fear losing the control over the class, not showing confidence in the method and not having the skills to effectively use this methodology. Similar to what was observed among students, some teachers also show resistance to these strategies because there is natural tendency, especially among secondary and higher education teachers, 'to teach the same way they have been taught', and to restrict their teaching environment to traditional methods based on information transfer (Halpern \& Hakel, 2003: p. 37; Mazur, 2009: p. 50).

The implementation of active instructional strategies requires changes in teacher's logic within the classroom environment. Unlike the traditional education which predefines the important topics in an organized, systematic and coherently presented way, so the students can learn; the active learning demands teachers to firstly establish the goals to be achieved and to choose one or more appropriate teaching strategies in order to reach these goals. Secondly, they must plan the class activities in order to encourage students to pursue the necessary knowledge to achieve the goals by elaborating questions, debates, activities, tasks, exercises, projects, challenges, etc.

\section{Conclusion}

Promoting active learning is not an easy task to be achieved, and teachers play a key role in its implementation process. The application of active methodologies is not just limited to 'try' a different pedagogical activity with the students or to promote debates in class. Actually, it means that the effective use of these techniques requires a new philosophical stance from both the teacher and the student. Such stance is essentially different from that observed in traditional lectures, which just expects the teacher to "teach" and the students, to "learn".

Often, just after the new teaching strategies are implemented that it is possible to recognize and overcome the knowledge transfer-based traditional lectures. This negative aspect of traditional methodologies may be summarized in the sentence by Mark Twain which is often quoted in the literature: "A lesson is the process in which the teacher's notes go straight to the students' notes, without passing through the brains of either."

How to develop active students? What does the teacher get by devoting him/herself to form active students? Are there any risks involved in it? May losses occur? What are the difficulties faced by teachers to form active students? Are the results worthy of the changing efforts? What are the new roles teachers and schools should play to form active students? Many questions still need answers. However, an essential element to overcome the problems and to promote changes in the current educational scenario concerns the learning process. One of the best ways to achieve these changes lies on the practice of active methodologies. Therefore, a good active methodology should be constructivist, collaborative, interdisciplinary, contextualized, reflective (always involving ethics and values), critical, investigative, motivating, challenging and humanist.

Active learning strategies have been increasingly used in school environments, as teachers learn their benefits. Studies have shown that the active learning improves the understanding and retention of information, and that it is effective to develop higher-order cognitive skills such as the problem-solving ability and critical thinking.

At the end of a positive active learning experience, both students and teachers will be benefited from the concepts described in the current paper. The definition of success in education should not be exclusively restricted to performance evaluations and approval rates - which, in a way, measure the quality of learning in our community; it must also include the meaning of a much larger, lasting and enjoyable experience, which is depicted by the real satisfaction of both the teacher and the student. 


\section{References}

Anastasiou, L. G. C., \& Alves, L. P. (2004). Estratégias de ensinagem. In L. G. C. Anastasiou, \& L. P. Alves (Orgs.), Processos de ensinagem na universidade. Pressupostos para as estratégias de trabalho em aula (3rd ed., pp. 67-100). Joinville: Univille.

Beichner, R. J. (2014). History and Evolution of Active Learning Spaces. New Directions for Teaching and Learning, 2014, 9-16. http://dx.doi.org/10.1002/tl.20081

Bloom, B. S. (1986). What We Are Learning about Teaching and Learning: A Summary of Recent Research. Principal, 66, 6-10.

Boekaerts, M. (1997). Self-Regulated Learning: A New Concept Embraced by Researchers, Policy Makers, Educators, Teachers, and Students. Learning and Instruction, 7, 161-186.

Boekaerts, M., Musso, M., \& Cascallar, E. (2012). Self-Regulated Learning and the Understanding of Complex Outcomes. Educational Psychology International, 2012, 1-81. http://dx.doi.org/10.1155/2012/686385

Bonwell, C. C., \& Eison, J. A. (1991). Active learning: Creating Excitement in the Classroom. ASHE-ERIC, Higher Education Report n. 1. Washington, DC: George Washington University.

Borrego, M., Cutler S., Prince, M., Henderson, C., \& Froyd, J.E. (2013). Fidelity of Implementation of Research-Based Instructional Strategies in Engineering Science Courses. Journal of Engineering Education, 102, 394-425. http://dx.doi.org/10.1002/jee.20020

Brockliss, L. (1996). Curricula. A History of the University in Europe (pp. 565-620). Cambridge (Reino Unido): Cambridge University Press, Vol. 2.

Coil, D., Wenderoth, M. P., Cunningham, M., \& Dirks, C. (2010). Teaching the Process of Science: Faculty Perceptions and an Effective Methodology. CBE-Life Sciences Education, 9, 524-535. http://dx.doi.org/10.1187/cbe.10-01-0005

Dewey, J. (1938). Experience and Education. New York: The Macmillan Company.

Doyle, T. (2008). Helping Students Learn in a Learner-Centered Environment: A Guide to Facilitating Learning in Higher Education. Sterling, VA: Stylus Publishing.

Eddy, S. L., Converse, M., \& Wenderoth, M. P. (2015). PORTAAL: A Classroom Observation Tool Assessing EvidenceBased Teaching Practices for Active Learning in Large Science, Technology, Engineering, and Mathematics Classes. Cell Biology Education-Life Sciences Education, 14, 1-16. http://dx.doi.org/10.1187/cbe.14-06-0095

Feynman, R. (1963). Lectures on Physics. http://www.feynmanlectures.info

Fox-Cardamone, L., \& Rue, S. (2003). Students’ Responses to Active-Learning Strategies: An Examination of Small-Group and Whole-Class Discussion. Research for Educational Reform, 8, 3-15.

Fraser, J. M., Tinman, A. L., Miller, K., Dowd, J. E., Tucker, L., \& Mazur, E. (2014). Teaching and Physics Education Research: Bridging the Gap. Reports on Progress in Physics, 77, 1-17. http://dx.doi.org/10.1088/0034-4885/77/3/032401

Freeman, S., Eddy, S. L., Mcdonough, M., Smith, M. K., Okoroafor, N., Jordt, H., \& Wenderoth, M. P. (2014). Active Learning Increases Students’ Performance in Science, Engineering, and Mathematics. Proceedings of the National Academy of Sciences of the United States of America, 111, 8410-8415. http://www.pnas.org/content/111/23/8410.full.pdf

Freire, P. (2011). Pedagogia do oprimido (50th ed.). Rio de Janeiro: Ed. Paz e Terra.

Gudwin, R. R. (2015). Aprendizagem ativa. N.p. http://faculty.dca.fee.unicamp.br/gudwin/activelearning

Hake, R. R. (1998). Interactive-Engagement vs. Traditional Methods: A Six-Thousand-Student Survey of Mechanics Test Data for Introductory Physics Courses. American Journal of Physics, 66, 64. http://dx.doi.org/10.1119/1.18809

Halpern, D. F., \& Hakel, M. D. (2003). Applying the Science of Learning to the University and Beyond: Teaching for Long-Term Retention and Transfer. Change, 35, 36-41. http://dx.doi.org/10.1080/00091380309604109

Harvey, W. (1628). Exercitatio anatomica de motu cordis et sanguinis in animalibus. Frankfurt: W. Fitzeri.

Hitchens, M., \& Lister, R. (2009). A Focus Group Study of Student Attitudes to Lectures. In M. Hamilton, \& T. Clear, Eds., Proceedings of the 11th Australasian Computing Education Conference (ACE 2009) (pp. 93-100). Wellington, New Zealand. CRPIT, 95. ACS, 20-23 January 2009. http://crpit.com/confpapers/CRPITV95Hitchens.pdf

Huitt, W. (1992). Problem Solving and Decision-Making: Consideration of Individual Differences Using the Myers-Briggs Type Indicator. Journal of Psychological Type, 24, 33-44.

Johnson, R. T., Johnson, D. W., \& Smith, K. A. (1998). Cooperative Learning. http://personal.cege.umn.edu/ smith/docs/CL\%20College-604.doc

Kwan, A. (2009). Problem-Based Learning. In M. Tight et al. (Eds.), The Routledge International Handbook of Higher Education (pp. 91-108). New York: Taylor \& Francis.

Laws, P., Sokoloff, D., \& Thornton, R. (1999). Promoting Active Learning Using the Results of Physics Education Research. 
UniServe Science News. http://sydney.edu.au/science/uniserve_science/newsletter/vol13/sokoloff.html

Lom, B. (2012). Classroom Activities: Simple Strategies to Incorporate Students-Centered Activities within Undergraduate Science Lectures. The Journal of Undergraduate Neuroscience Education, 11, A64-A71.

Luckesi, C. C. (1994). Filosofia da educação. São Paulo: Cortez.

Marcondes, F. K., Moura, M. J., Sanches, A., Costa, R., de Lima, P. O., Groppo, F. C. et al. (2015). A Puzzle Used to Teach the Cardiac Cycle. Advances in Physiology Education, 39, 27-31. http://dx.doi.org/10.1152/advan.00116.2014

Mazur, E. (2009). Farewell, Lecture? Science, 323, 50-51. http://dx.doi.org/10.1126/science.1168927

Mckeachie, W. J. (1987). Can Evaluating Instruction Improve Teaching? New Directions for Teaching and Learning, 31 , 3-7. http://dx.doi.org/10.1002/tl.37219873103

Moreira, M. B., \& Manfroi, W. (2011). O papel da aprendizagem baseada em problemas nas mudanças no ensino médico no Brasil. Revista HCPA, 31, 477-481.

Petty, G. (2014). Teaching Today: A Practical Guide (5th ed.). Oxford: Oxford University Press.

Prince, M. J. (2004). Does Active Learning Work? A Review of the Research. Journal of Engineering Education, 93, 223231. http://dx.doi.org/10.1002/j.2168-9830.2004.tb00809.x

Ramos, C. (1992). William Harvey: Vida e obra (2ª parte). Acta Médica Portuguesa, 5, 559-563.

Ramsden, P. (1992). Learning to Teach in Higher Education (pp. 154-156). London: Routledge. http://dx.doi.org/10.4324/9780203413937

Rowe, M. B. (1980). Pausing Principles and Their Effects on Reasoning in Science. In F. B. Brawer (Ed.), Teaching the Sciences: New Directions for Community Colleges (pp. 27-34). San Francisco: Jossey-Bass. http://dx.doi.org/10.1002/cc.36819803106

Slamecka, N. J., \& Graf, P. (1978). The Generation Effect: Delineation of a Phenomenon. Journal of Experimental Psychology: Human Learning and Memory, 4, 592-604. http://dx.doi.org/10.1037/0278-7393.4.6.592

Stuart, J., \& Rutherford, R. J. (1978). Medical Student Concentration during Lectures. The Lancet, 312, 514-516. http://dx.doi.org/10.1016/S0140-6736(78)92233-X 